Article

\title{
Numerical Simulation of the Impact of Unmined Longwall Panel on the Working Stability of a Longwall Using UDEC 2D-A Case Study
}

\author{
Sylwester Rajwa ${ }^{1}$, Tomasz Janoszek ${ }^{1, *} \mathbb{0}$, Janina Świątek ${ }^{1}$, Andrzej Walentek ${ }^{1}$ and Dominik Bałaga $^{2} \mathbb{0}$ \\ 1 Department of Extraction Technologies, Rockburst and Risk Assessment, Central Mining Institute, Plac \\ Gwarków 1, 40-166 Katowice, Poland; srajwa@gig.eu (S.R.); jswiatek@gig.eu (J.Ś.); awalentek@gig.eu (A.W.) \\ 2 KOMAG Institute of Mining Technology, Division of Machines and Devices, Pszczyńska 37, \\ 44-100 Gliwice, Poland; dbalaga@komag.eu \\ * Correspondence: tjanoszek@gig.eu; Tel.: +48-32-259-23-07
}

check for

updates

Citation: Rajwa, S.; Janoszek, T.;

Świątek, J.; Walentek, A.; Bałaga, D.

Numerical Simulation of the Impact of Unmined Longwall Panel on the Working Stability of a Longwall Using UDEC 2D-A Case Study. Energies 2022, 15, 1803. https:// doi.org/10.3390/en15051803

Academic Editors: Yulong Chen, Junwen Zhang, Jianhang Chen and Xuejie Deng

Received: 13 January 2022

Accepted: 23 February 2022

Published: 28 February 2022

Publisher's Note: MDPI stays neutral with regard to jurisdictional claims in published maps and institutional affiliations.

Copyright: (c) 2022 by the authors. Licensee MDPI, Basel, Switzerland. This article is an open access article distributed under the terms and conditions of the Creative Commons Attribution (CC BY) license (https:// creativecommons.org/licenses/by/ $4.0 /)$.

\begin{abstract}
The main goal of the paper is numerical simulation for investigation of damage causes in the working of a longwall located under the unmined longwall panel. The paper presents the results of model-based research on the stability of the roof of a longwall working in a zone subject to cave-in mining, taking into account the influence of mining conditions in the form of an unmined coal seam located $115 \mathrm{~m}$ above the exploited seam. It presents the geometry of the rock mass under study, the discretization area of the solution, and gives an overview of the assumptions used to build the numerical model. The authors discuss the results of numerical simulations of the influence of mining phenomena on the formation of roof falls in the longwall. Based on the results of numerical simulations, the process of identifying the size of roof falls in a longwall working (loss of stability) was carried out through their appropriate classification. The case presented and analyzed in this paper occurred in one of Poland's coal mines.
\end{abstract}

Keywords: roof fall; numerical modeling; stability; longwall working; unmined longwall panel

\section{Introduction}

For longwall workings, an important factor affecting their stability is the changes occurring in the rock mass caused by the exploitation of seam and adjacent seams [1-6]. Ensuring longwall workings stability under the conditions of coal seam mining with the roof directed towards the caving process is a key issue for mining departments and for production preparation and planning, which are responsible for proper operation of mining plants [7]. The occurrence of roof falls in longwalls, apart from posing a danger to the working personnel, also has a negative impact on the efficiency of the entire hard coal mine. This relates both to a limitation of the daily progress of the longwall and to the incorrect operation of the powered longwall system elements, in particular, the powered roof supports constituting the basic protection of the longwall face [5,8-12]. Three forms of loss of stability of the longwall working can be distinguished, i.e., minor roof fall, medium roof fall and major roof fall as shown in Figure $1[1,5,8,13,14]$. 


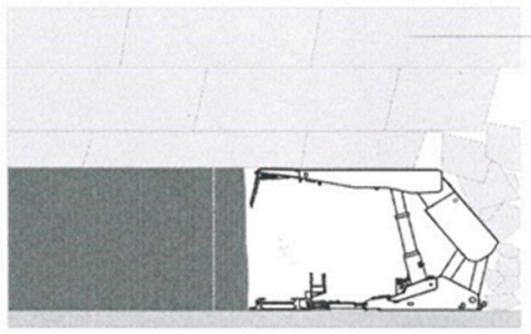

(a)

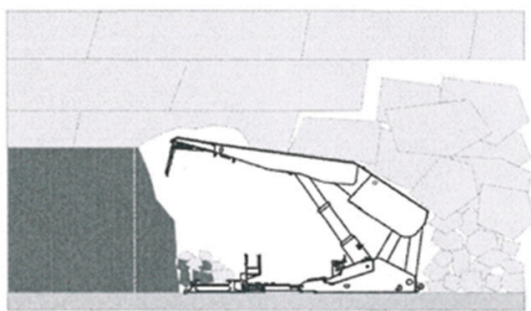

(c)

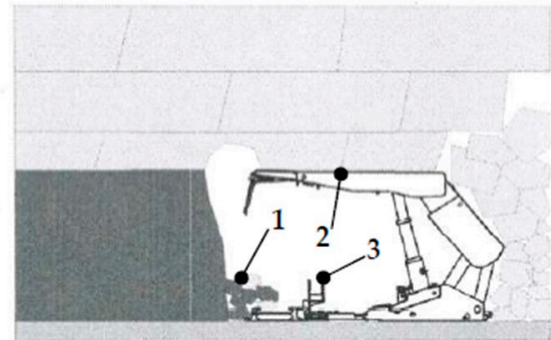

(b)

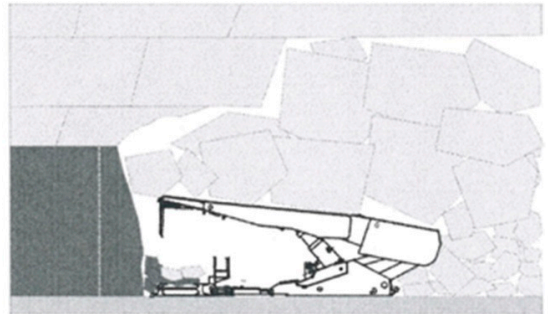

(d)

Figure 1. Roof fall progress in the working of a longwall: (a)—stable condition, (b)—unstable condition resulting in minor roof fall, (c) - unstable condition resulting in medium roof fall, (d) unstable condition resulting in major roof fall, 1-roof fall, 2-canopy, 3-armored face conveyor (AFC) (Source: Own elaboration).

The factors determining the formation of roof falls in longwalls can be divided into three main groups: geological, mining and technical $[5,8,9]$. According to the stratification analysis [14] carried out, the causes that have the greatest influence on the possibility of a roof fall include $[4,15,16]$ :

- $\quad$ The presence of faults;

- Type and strength parameters of rocks;

- The tendency of the coal face to splinter;

- Insufficient initial support of powered roof supports (up to that specified in the roof support's documentation);

- Insufficient working support of powered roof supports (up to that specified in the roof support's documentation);

- $\quad$ Low strength parameters of the coal seam $R_{c}<10 \mathrm{MPa}$;

- The depth of longwall panel;

- The large width of the front path;

- The initial support capacity of powered roof supports is too high (in comparison with the support's documentation).

The factors listed above correspond to a large extent to the observations made in the in-situ conditions of the longwalls where the roof falls occurred. The experience gathered during observations of longwall running was included in the catalogue of roof falls (2016-2020) developed as part of the long-term statutory work conducted at the Central Mining Institute. This article presents the results of numerical simulations of the influence of unmined longwall panel on the formation of a roof fall in a longwall working, carried out with caving, based on a selected example.

An innovation of the paper is the possibility of forecasting geometric parameters of defining the range of roof displacement in the working of a longwall using is a twodimensional numerical program that simulates the quasi-static response to loading of the rock mass containing multiple intersecting joint structures [17]. In addition, based on the results of the numerical simulation, it is possible to estimate and classify the roof fall in the working of a longwall for a given mining and geological conditions and technical parameters of powered roof support. Obtained results of numerical model and proposed 
method of the roof fall type classification can be useful forward at the stage of mining planning.

Results from the numerical simulations with in-situ observations allowed the formulation of the concept of the effect of vertical stress, which takes into account the influence of the edges of unmined longwall panel laying above the exploiting coal seam on the stress state in the longwall working surroundings.

Model tests were conducted using the discrete element method based on the UDEC ver.4.0 Lagrange computational scheme [17]. The UDEC calculation code allows the modelling of large displacements and deformations of objects characterized by a block structure. The code makes it possible to predict the impact of reduced cohesion and fractures in the rock mass on the stability of underground workings [18].

\section{Materials and Methods}

\subsection{In-Situ Tests}

Figure 2 presents a map of the roof fall in a longwall panel A. At the moment of the roof fall, the front of the longwall was at approximately $495 \mathrm{~m}$ of its run-out, with approximately $145 \mathrm{~m}$ remaining until its completion. The length of the longwall was about $150 \mathrm{~m}$, the inclination of the seam in the longwall area was about $+4^{\circ}$. When the rock fall occurred, the front of the longwall was in the area of influence of the unmined longwall panel B deposited above the longwall panel A. The distance between the seam A and the seam B was approximately $115 \mathrm{~m}$. At the time of the underground in-site inspection, the situation in the longwall was as follows:

- From the front drive of the conveyor to section No. 55, exploitation in the longwall was carried out with a coal seam 0.2 to $0.4 \mathrm{~m}$ thick in the roof;

- From section 85 in the direction of the rear conveyor drive, mining was carried out with a coal seam between 0.2 and 0.5 m thick in the roof;

- Sections from No. 70 to No. 76 were run on a coal bottom.

The probable cause of the loss of stability of the longwall workings in the seam A was the influence of the edge of the unmined longwall panel in the seam B. An increase in the load on the powered section from the rock mass, manifested by coal face slumps and roof falls into the area unsupported by the powered roof supports operating in this section of the longwall panel. These difficulties made it impossible to build the sections with the correct geometry of their operation, which made it impossible to obtain the correct initial support of the sections. As a result of the incorrect geometry, the canopy of the powered roof support supported the roof unevenly (at points, e.g., by the edge of the canopy), which resulted in the roof fall and significant damage to the main roof. According to the underground measurements carried out as shown in Figure 3, the largest fall of the roof in the working of a longwall panel A occurred in the direction of coal face (" $y$ " according to Figure $3 \mathrm{a}$ ) above the sections from 56 to 84 (number of sections during the roof falls $i=28$ ), and maximum high of roof fall was $2.5 \mathrm{~m}$ (" $x$ " according to Figure 3a) above the canopy (red area in Figure 2b).

\subsection{Numerical Model}

\subsubsection{Geometry}

To demonstrate the influence of the located above coal seam B on the stability of the longwall workings in the seam A, it was decided to consider the following three variants of conducting model tests:

- Variant I-represents the numerical model of the rock mass in which the longwall in the seam A is carried out in conditions of the lack of relaxation of the rock mass (no exploitation of the seam B) (Figure 4);

- Variant II-represents the numerical model of the rock mass, where the longwall in the seam $\mathrm{A}$ is operated in the conditions of the rock mass relaxed by the earlier exploitation of the seam B (Figure 5); 
- Variant III-represents the numerical model of the rock mass in which the longwall in the seam A is carried out under the influence of the remaining part of the seam B (Figure 6).

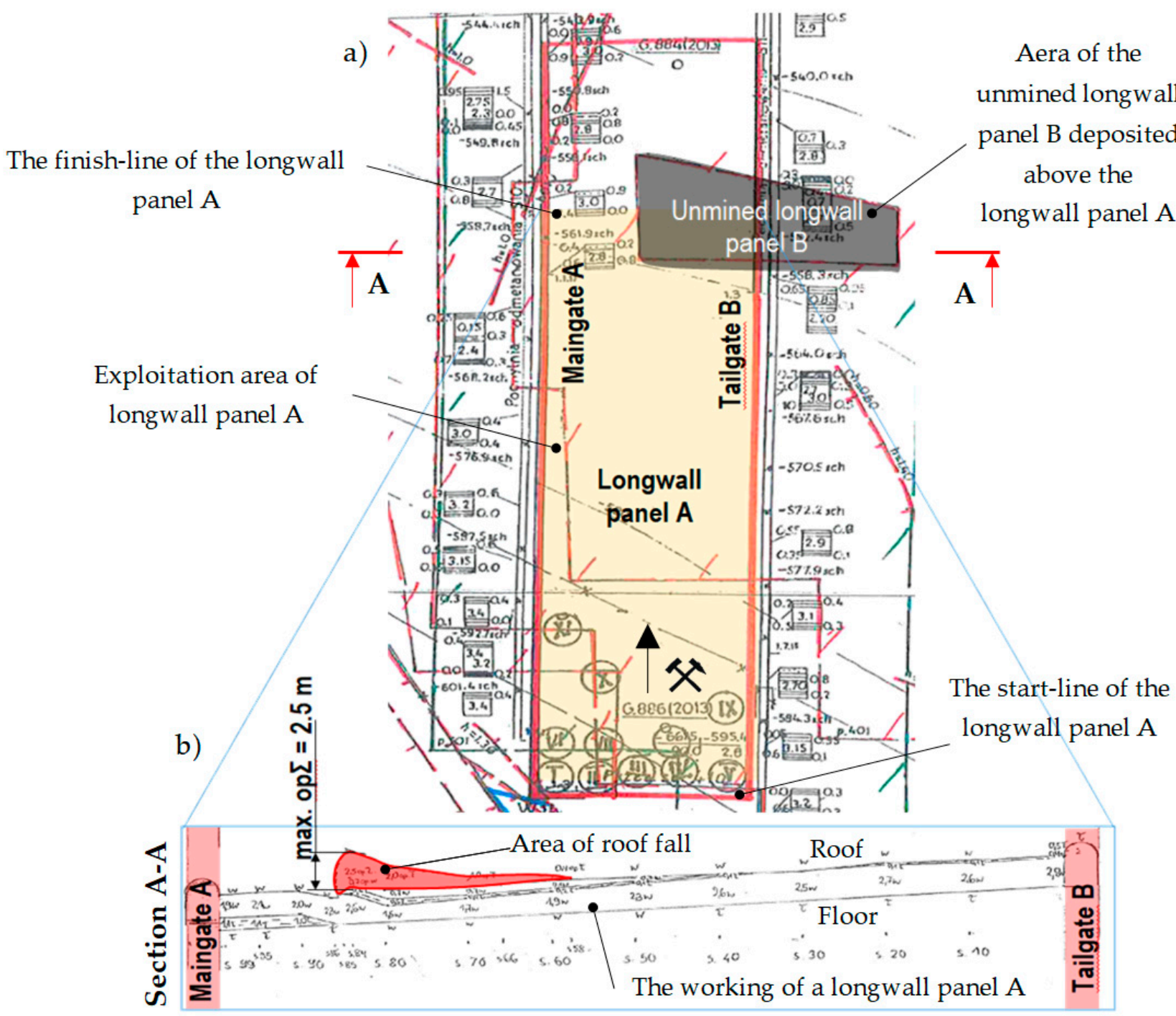

Figure 2. Map of the exploited coal seam A (a) and measurement sketch (b) of the height of exposure in the roof of the longwall working, where: s. - section number, w-thickness of coal seam, op $\Sigma$-the height of exposure of the roof in the longwall workings.

a)

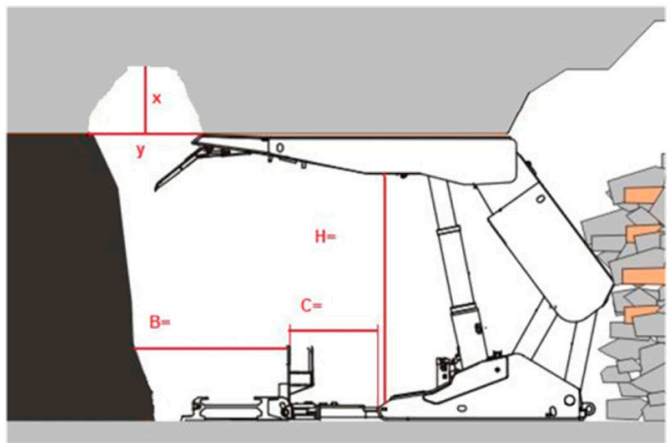

Figure 3. Geometric parameters of the roof fall in the working of a longwall: (a) measurement sketch, (b) situation sketch in the longwall working during roof fall (Source: Own elaboration). 


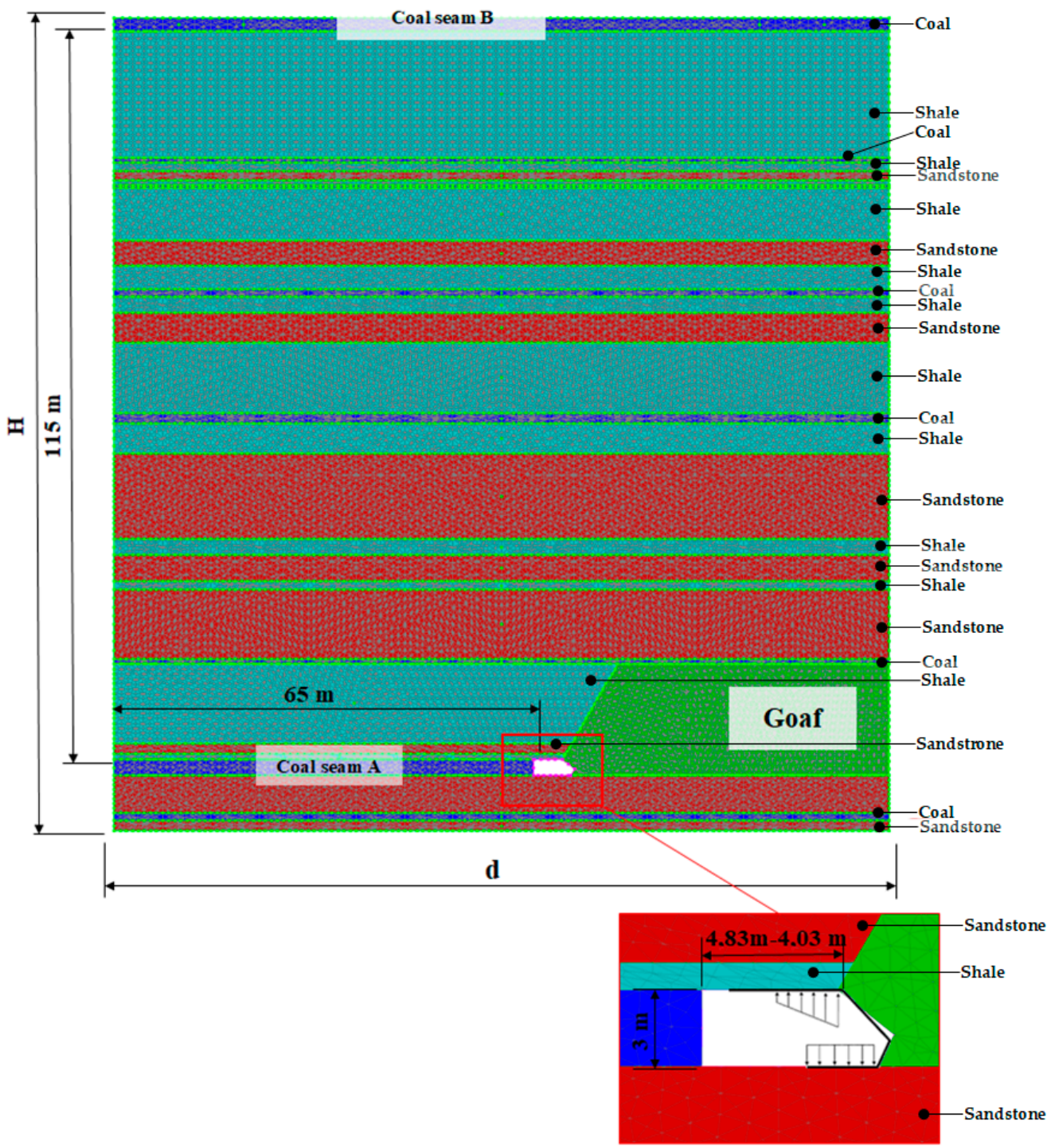

Figure 4. Numerical grid of the cross-section of the analyzed rock mass for variant I.

The numerical model in Figure 4 represents the geometry of the rock mass in the condition of conducting a longwall in a seam A with caving. Above the coal seam A is a coal seam B with thickness $2.0 \mathrm{~m}$ (that represents variant I of the calculation). The height of the coal face in the seam $\mathrm{A}$ is $3.0 \mathrm{~m}$, the longwall workings range from 4.03 to $4.83 \mathrm{~m}$, and the length of the longwall is $200 \mathrm{~m}$. The seam A is located at a depth of approximately $875 \mathrm{~m}$. The analysed longwall has made about $500 \mathrm{~m}$ of progress since its starting, and about $150 \mathrm{~m}$ remain to be completed. For the analysis, a numerical grid section of dimensions: length $\mathrm{d}=120 \mathrm{~m}$, height $\mathrm{H}=126 \mathrm{~m}$ was used, which contains the necessary information regarding the rock formations for the analysis.

The numerical model in Figure 5 represents the geometry of the rock mass in the case of a longwall with caving in relaxed rock mass condition (represents variant II of calculation).

The model in Figure 6 represents the geometry of a longwall with caving, taking into account the effect of a mining event in the form of an unmined longwall panel in the seam B with a thickness of $2.0 \mathrm{~m}$ and width of $80.0 \mathrm{~m}$ (that represents variant III of calculation). 


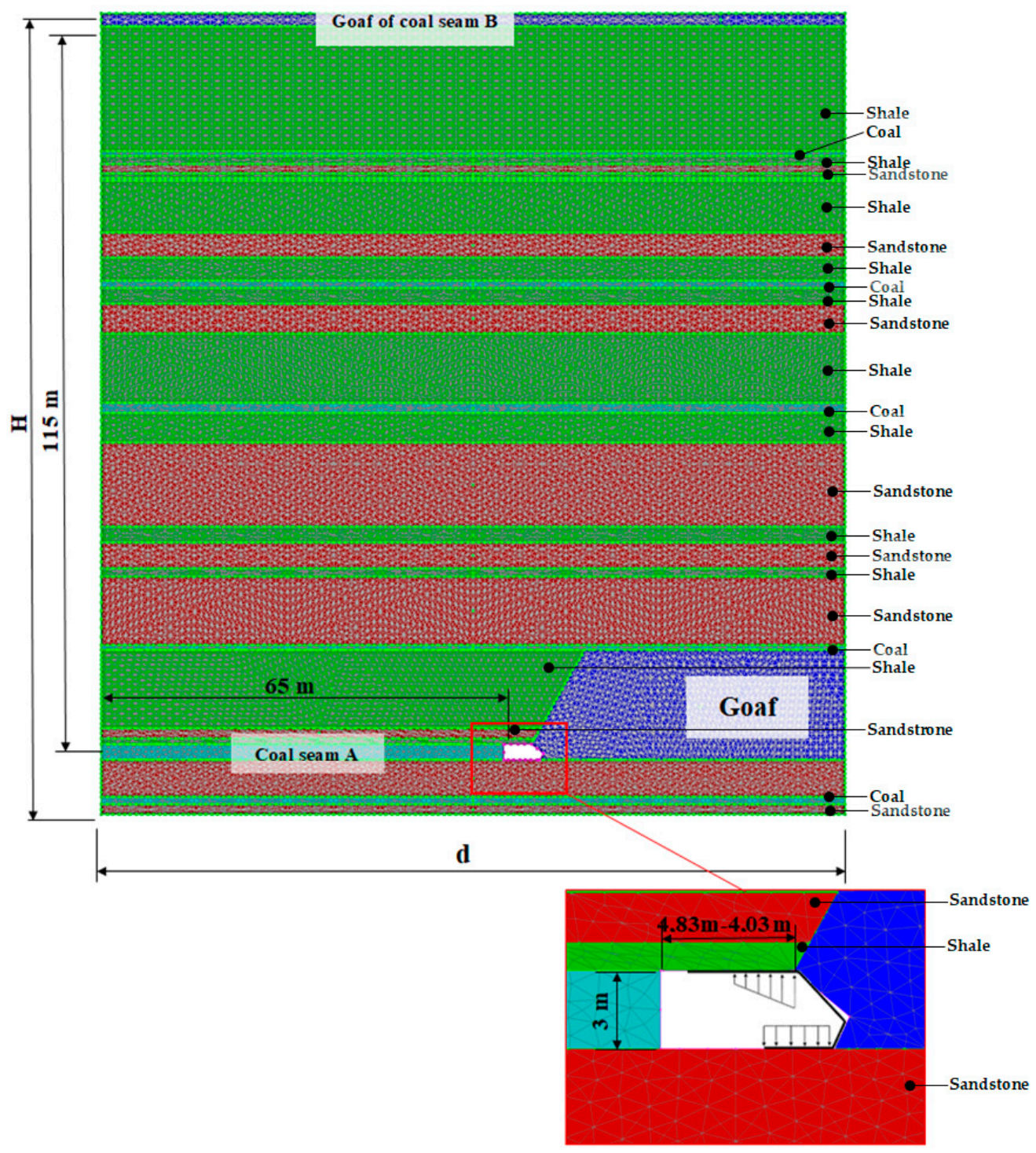

Figure 5. Numerical grid of the cross-section of the analyzed rock mass for variant II.

Dimensions of the rock mass model shown in Figures 5 and 6 are similar to dimensions of the rock mass model shown in Figure 4.

\subsubsection{Mesh Density Study}

Before using the discretized geometry for numerical calculations, the mesh density were considered. Figure 7 shows the mesh density study on the pressure results in the rock mass model. 


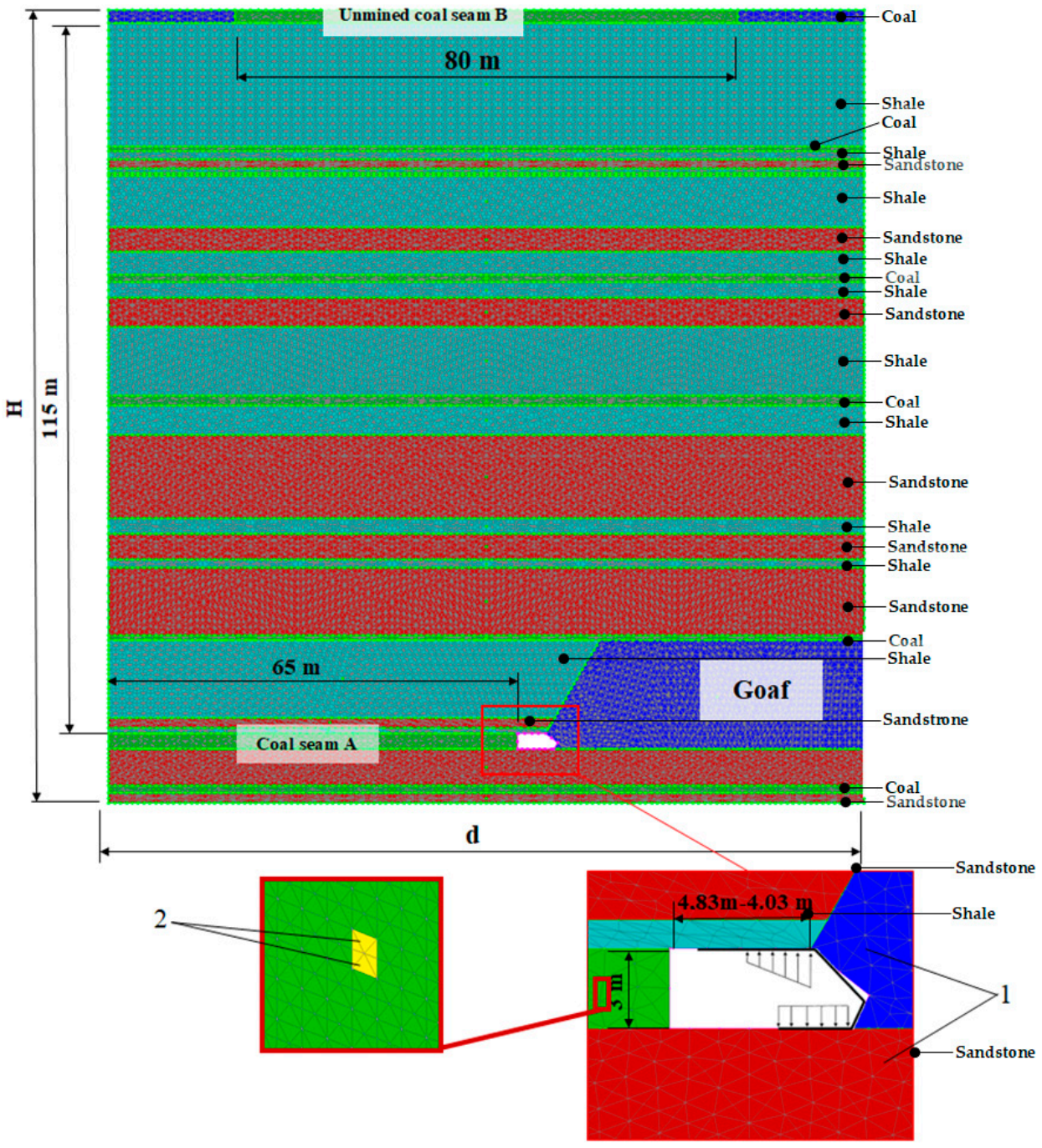

Figure 6. Numerical grid of the cross-section of the analyzed rock mass for variant III: 1—blocks, 2-deformed zones.

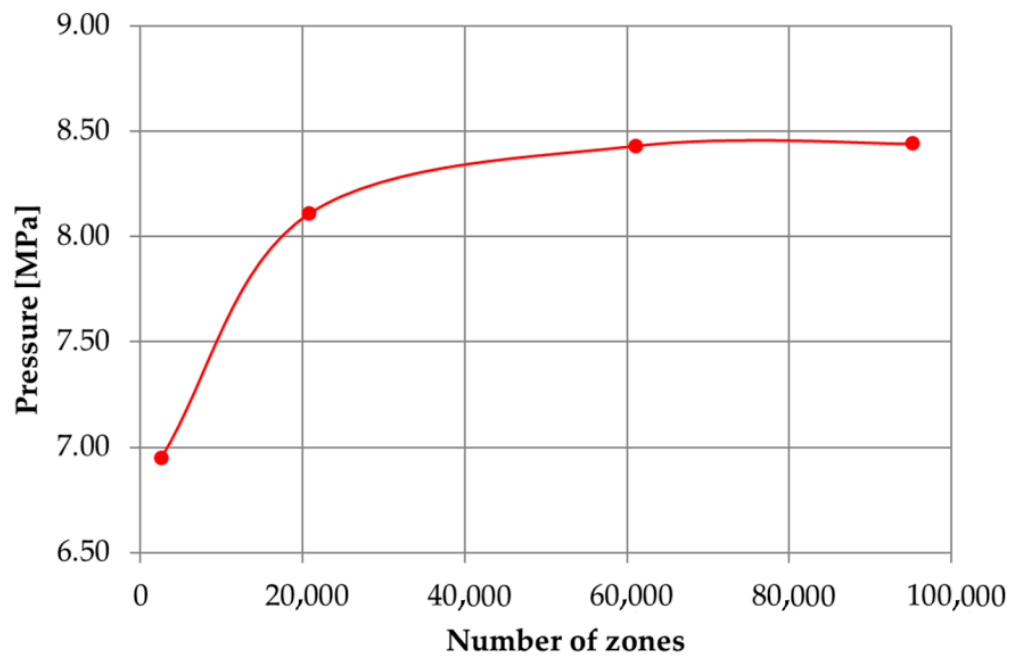

Figure 7. Convergence of results in the numerical grid density study.

The results of the four numerical grid densities were compared in Table 1. 
Table 1. Results of numerical grid density study.

\begin{tabular}{cccc}
\hline No. & Mesh Quality & Number of Zones & Pressure [MPa] \\
\hline 1 & coarse & 2569 & 6.950 \\
2 & normal & 20,863 & 8.110 \\
3 & fine & 61,083 & 8.435 \\
4 & very fine & 95,255 & 8.439 \\
\hline
\end{tabular}

It was decide to generate a numerical grid with an area of $15,096 \mathrm{~m}^{2}$, composed of 32 blocks (Figure 6 (1)) and 61,083 zones, which represent the individual rock layers in the rock mass model. The selected blocks are discretized into deformable zones (Figure 6 (2)).

\subsubsection{Assumptions}

The numerical model was based on the mechanical parameters summarized in Tables 1 and 2. The rock mass model is an elastic-plastic medium with a Coulomb-Mohr strength criterion for the parameters shown in Table 2.

Table 2. Mechanical parameters of rocks and goaf adopted for calculations.

\begin{tabular}{|c|c|c|c|c|c|c|c|c|c|}
\hline Rock & $\underset{\mathrm{kg} / \mathrm{m}^{3}}{\rho}$ & $\begin{array}{l}v \\
-\end{array}$ & $E \times 10^{9} \mathrm{~Pa}$ & $K \times 10^{9} \mathrm{~Pa}$ & $G \times 10^{9} \mathrm{~Pa}$ & $R_{c} \times 10^{6} \mathrm{~Pa}$ & $R_{m} \times 10^{6} \mathrm{~Pa}$ & $\begin{array}{c}\varphi \\
\text { deg }\end{array}$ & $c_{M} \underset{\mathrm{Pa}}{\times 10^{6}}$ \\
\hline Shale & 2670 & 0.29 & 17.80 & 14.12 & 6.89 & 31.90 & 1.75 & 25.5 & 6.20 \\
\hline Coal seam & 1450 & 0.25 & 4.05 & 2.70 & 1.62 & 18.40 & 1.01 & 24.45 & 11.50 \\
\hline Sandstone & 2510 & 0.28 & 19.90 & 27.60 & 7.20 & 39.70 & 2.18 & 25.50 & 7.70 \\
\hline Goaf & 1500 & 0.40 & 0.10 & 0.16 & 0.03 & - & - & - & - \\
\hline
\end{tabular}

Symbols: $\rho$-density, $v$-Poisson's ratio, E-Young's modulus, $K$-bulk modulus (Helmholtz modulus) $G$-stiffness modulus (Kirchhoff modulus), $R_{c}$ - uniaxial compressive strength, $R_{m}$ - uniaxial tensile strength, $\varphi$-angle of internal friction, $c_{M}$ - cohesion.

The joint parameters between blocks were defined by a Coulomb slip constitutive model based on the data in Table $3[19,20]$.

Table 3. Joint parameters adopted for calculations [17].

\begin{tabular}{cccc}
\hline $\begin{array}{c}\text { Joint Contact } \\
\text { between Blocks }\end{array}$ & $\begin{array}{c}\text { Normal Stiffness } \\
{[\mathbf{P a} / \mathbf{m}]}\end{array}$ & $\begin{array}{c}\text { Tangential Stiffness } \\
{[\mathbf{P a} / \mathbf{m}]}\end{array}$ & $\begin{array}{c}\text { Int. Friction Angle } \\
{\left[{ }^{\circ}\right]}\end{array}$ \\
\hline sandstone-coal & $3.05 \times 10^{9}$ & $2.35 \times 10^{9}$ & 10 \\
shale-coal & $3.29 \times 10^{9}$ & $1.9 \times 10^{9}$ & 14 \\
shale-shale & $1.0 \times 10^{10}$ & $1.0 \times 10^{9}$ & 26 \\
sandstone-sandstone & $1.0 \times 10^{10}$ & $1.0 \times 10^{9}$ & 29 \\
\hline
\end{tabular}

The basic parameter of the model is the volumetric stiffness modulus $K$ interpreted by the formula [17]:

$$
K=\frac{E}{3 \times(1-2 v)}
$$

and the shear modulus $G$ defined by [17]:

$$
G=\frac{E}{2 \times(1+v)}
$$

where:

E-Young's modulus.

$v$-Poisson's ratio.

The model includes the following boundary conditions $[11,17,21]$ :

- Lower and upper edge: displacement condition (velocity $y=0$ );

- Side edges: displacement condition (velocity towards $x=0$ ); 
- Model subjected to gravity $g=9.81 \mathrm{~m} \cdot \mathrm{s}^{-2}$.

The following convergence criterion of numerical model was considered:

- Solve step limit is 100,000;

- Ratio limit calculation is average;

- Steady-state ratio is $1.0 \times 10^{-5}$.

The vertical stress gradient in the rock mass model was determined by the relationship defined by [22]:

$$
q=0.02 \times G \times m_{c} \times \cos \alpha
$$

where:

G-mining depth, $\mathrm{m}$.

$m_{c}$-rock mass modification factor $\left(m_{c}=0.5\right.$ was assumed).

$\alpha$-inclination angle of the seam $\left(\alpha=0^{\circ}\right)$, deg.

q-pressure, Mpa.

The stress gradient was applied to all zones and contacts as an initial conditions. The stress gradient depends basically on the depth of mining. In fact, the author in [22] noticed that locally it can be even a dozen times higher and in other places much lower than the value resulting from the mining depth. Such a phenomenon is depended on the both natural and technical factors. The rock mass modification factor is the product of a partial factors, specific to the operational field and was estimated from the work [22] obtaining the value of 0.5 for a given geo-mining condition.

The effects of implementing the relation described by Equation (3) in the numerical model are illustrated in Figure 8. Figure 8 presents the map of changes of stresses in the rock mass model intact with exploitation at the depth from $758.5 \mathrm{~m}$ to $884.5 \mathrm{~m}$.

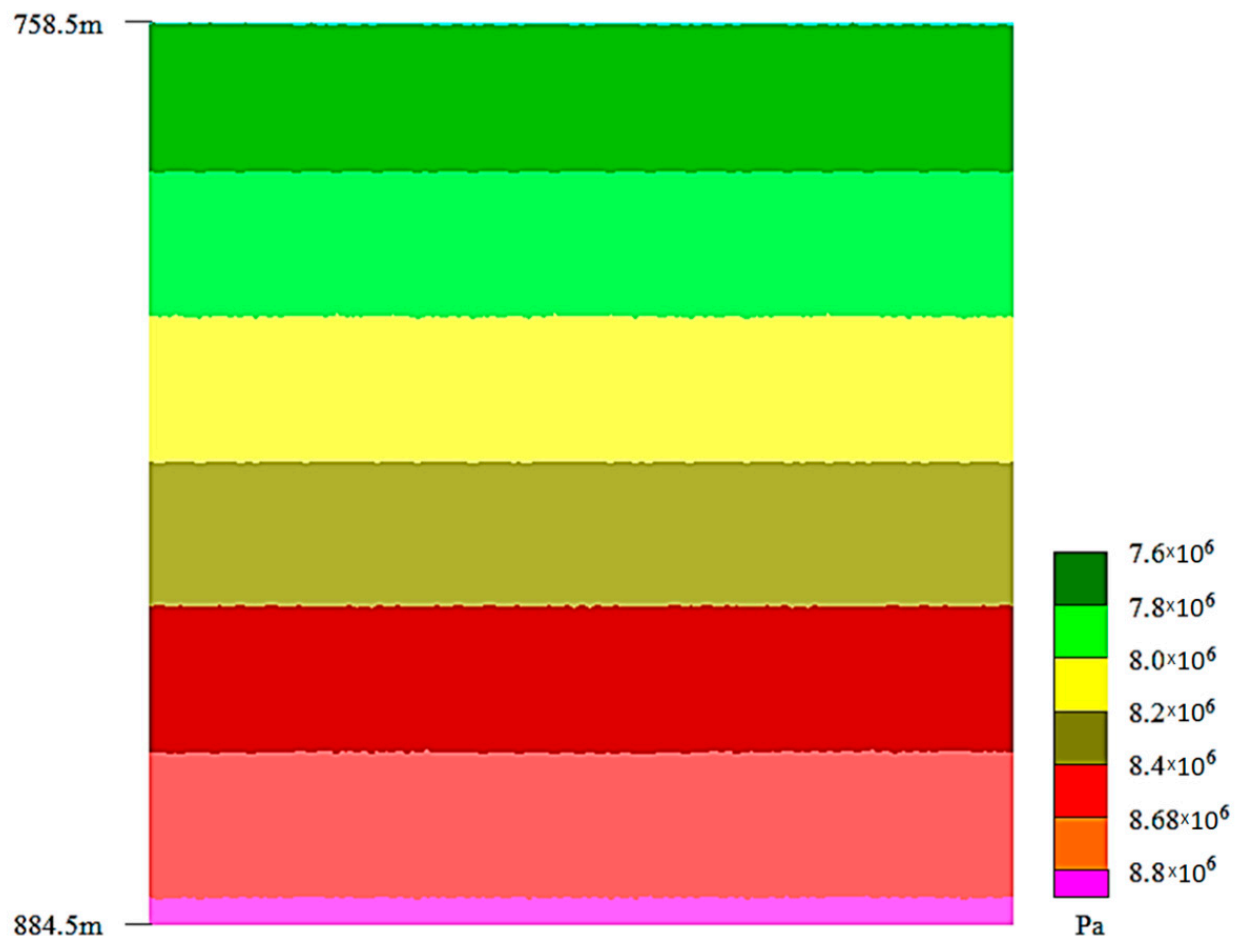

Figure 8. Map of the initial vertical stress gradient in the rock mass model.

For this analysis, it is assumed that the stability of a longwall working is secured by the powered roof support $[23,24]$. The geometry and distribution of forces and pressures along the canopy and the base are shown in Figure 9. The static analysis presented in Figure 9 is the initial condition for obtaining the numerical model solution. 


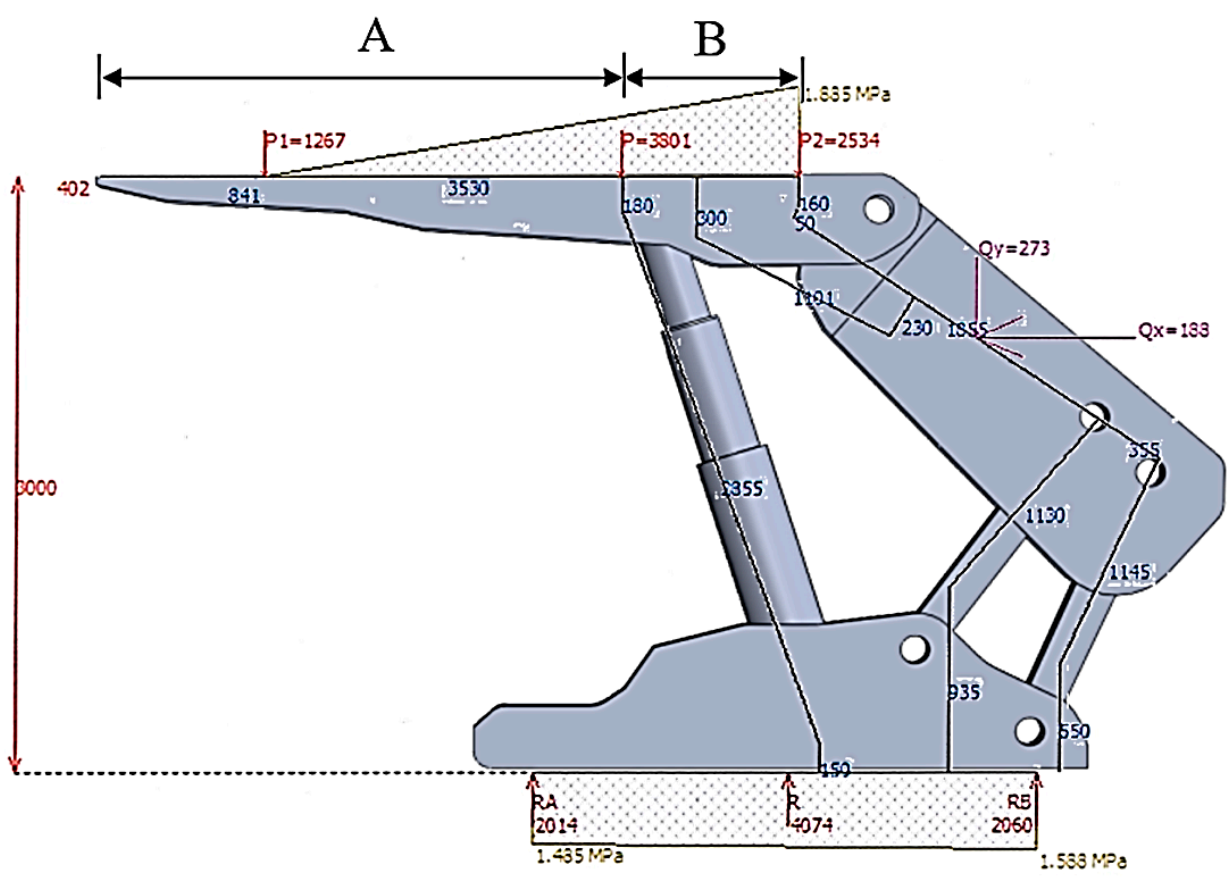

Figure 9. Distribution of forces and pressures along the canopy and the base of powered roof supports due to interaction with the rock mass, where: A-distance from the beginning of the canopy to the hydraulic leg socket, B-distance from the end of the canopy to the hydraulic leg socket.

The pressure distribution along the canopy of the 2-leg shield shows a trapezoidal distributed loading characteristic with a maximum value of approx. $1.90 \mathrm{Mpa}$. The pressure distribution along the base shows a rectangular distributed loading characteristic with minimum and maximum values of approx. $1.50 \mathrm{Mpa}$ and $1.60 \mathrm{Mpa}$, respectively.

Figure 10 shows the distribution of load changes on the roof and floor of the rock mass that was adopted for calculations in the developed numerical model.

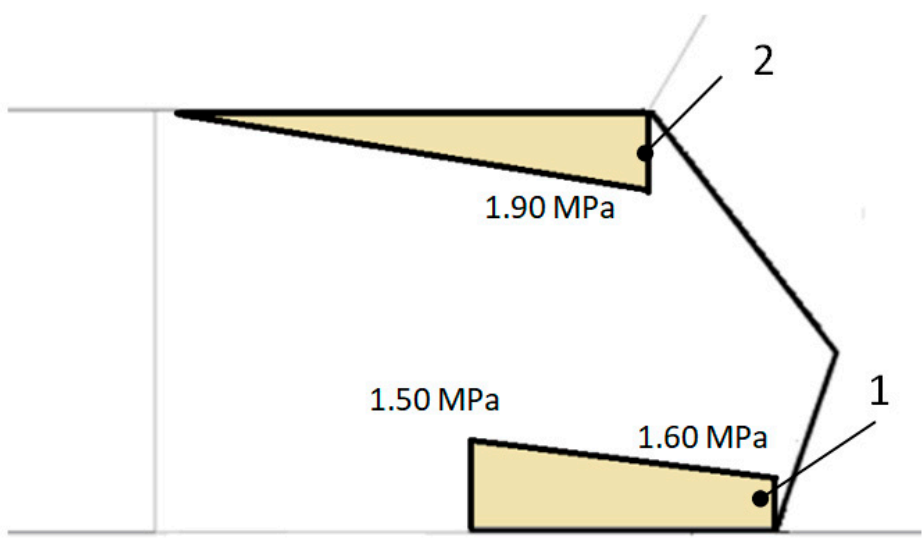

Figure 10. The distribution of load values along the roof (2) and floor (1) in the working of a longwall model.

The calculations were done for the following parameters of the powered roof support:

- Friction coefficient (roof support-rock mass) $-\mu=0.3$,

- Working height of the 2-leg shield $-1.6 \div 3.2 \mathrm{~m}$,

- 2-leg shield width-1.5 m,

- Diameter of 1st stage of hydraulic legs- $\varnothing 280 \mathrm{~mm}$,

- Initial hydraulic leg support/supply pressure-1.54 MN/25 Mpa,

- Working bearing capacity of the leg-2.28 MN/38 Mpa, 
- Canopy ratio-3.93 (proportion of length A to length B according to Figure 9).

Numerical simulations were carried out for two scenarios of longwall workings in the seam A:

- $\quad$ Before the web cut (distance from coal face is $\mathrm{L}=0.5 \mathrm{~m}$ )-Figure 11,

- $\quad$ After the web cut (distance from coal face is $\mathrm{L}=1.3 \mathrm{~m}$ )-Figure 11.

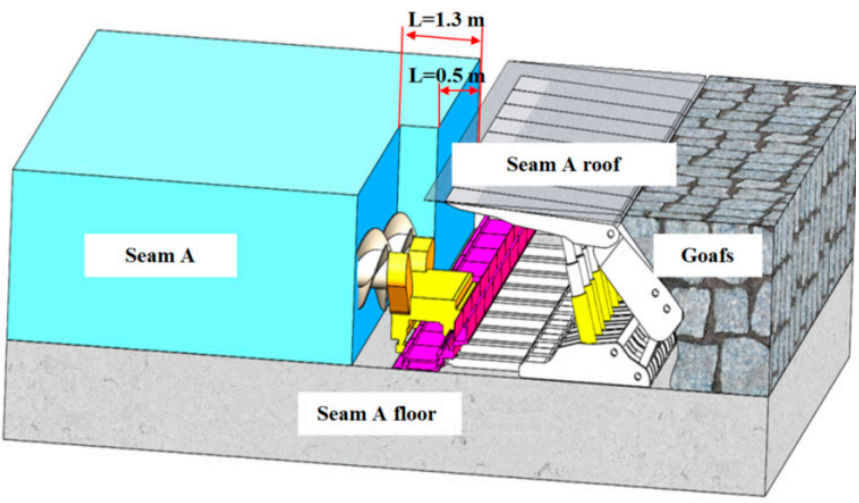

Figure 11. Distance from coal face $(\mathrm{L})$ before $(\mathrm{L}=0.8 \mathrm{~m})$ and after $(\mathrm{L}=1.3 \mathrm{~m})$ the web cut (Source: Own elaboration).

\section{Results}

Based on numerical calculations the range of roof displacement in the longwall working was developed (Figure 12). The issue of the impact of the unmined longwall panel located in the coal seam B and its influence on the process of roof fall formation in the longwall (Figures 13-15) was calculated. The characteristics of changes in the stress are shown in Figure 16. Results of numerical calculations simulate the loss of stability of the longwall working. The results of the numerical model were listed in Table 4 and forecast the changes in the range of the roof displacement $(X)$ and the values of displacement of roof rocks $(\mathrm{P})$ depending on the distance from coal face.

Table 4. Results of numerical simulation.

\begin{tabular}{|c|c|c|c|c|c|c|c|c|c|c|c|}
\hline \multicolumn{4}{|c|}{ Variant I } & \multicolumn{4}{|c|}{ Variant II } & \multicolumn{4}{|c|}{ Variant III } \\
\hline \multicolumn{2}{|c|}{$\mathrm{L}=0.5 \mathrm{~m}$} & \multicolumn{2}{|c|}{$\mathrm{L}=1.3 \mathrm{~m}$} & \multicolumn{2}{|c|}{$\mathrm{L}=0.5 \mathrm{~m}$} & \multicolumn{2}{|c|}{$\mathrm{L}=1.3 \mathrm{~m}$} & \multicolumn{2}{|c|}{$\mathrm{L}=0.5 \mathrm{~m}$} & \multicolumn{2}{|c|}{$\mathrm{L}=1.3 \mathrm{~m}$} \\
\hline $\mathrm{X}[\mathrm{m}]$ & $\mathrm{P}[\mathrm{m}]$ & $\mathrm{X}[\mathrm{m}]$ & $\mathrm{P}[\mathrm{m}]$ & $\mathrm{X}[\mathrm{m}]$ & $\mathrm{P}[\mathrm{m}]$ & $\mathrm{X}[\mathrm{m}]$ & $\mathrm{P}[\mathrm{m}]$ & $\mathrm{X}[\mathrm{m}]$ & $\mathrm{P}[\mathrm{m}]$ & $\mathrm{X}[\mathrm{m}]$ & $\mathrm{P}[\mathrm{m}]$ \\
\hline 0 & 0.0085 & 0 & 0.011 & 0 & 0.0125 & 0 & 0.0155 & 0 & 0.0087 & 0 & 0.009 \\
\hline 0.0178 & 0.00831 & 0.0462 & 0.0104 & 0.17 & 0.0121 & 0.17 & 0.015 & 0.16 & 0.00865 & 0.0535 & 0.00891 \\
\hline 0.19 & 0.0071 & 0.201 & 0.00852 & 0.432 & 0.0102 & 0.432 & 0.0121 & 0.509 & 0.00739 & 0.319 & 0.00842 \\
\hline 0.456 & 0.00655 & 0.508 & 0.00791 & 0.442 & 0.0099 & 0.442 & 0.0114 & 0.861 & 0.00694 & 0.532 & 0.00832 \\
\hline 0.915 & 0.00518 & 0.815 & 0.00764 & & & & & & & 0.795 & 0.00794 \\
\hline & & 0.917 & 0.00678 & & & & & & & 0.905 & 0.00707 \\
\hline & & 1.07 & 0.00654 & & & & & & & 1.32 & 0.00685 \\
\hline & & 1.53 & 0.00636 & & & & & & & 1.43 & 0.00678 \\
\hline & & 2.19 & 0.0062 & & & & & & & 2.01 & 0.00648 \\
\hline & & & & & & & & & & 2.50 & 0.00602 \\
\hline
\end{tabular}

Symbols: L—distance from coal face (Figure 8), X—range of roof displacement, $\mathrm{P} —$ displacement. 


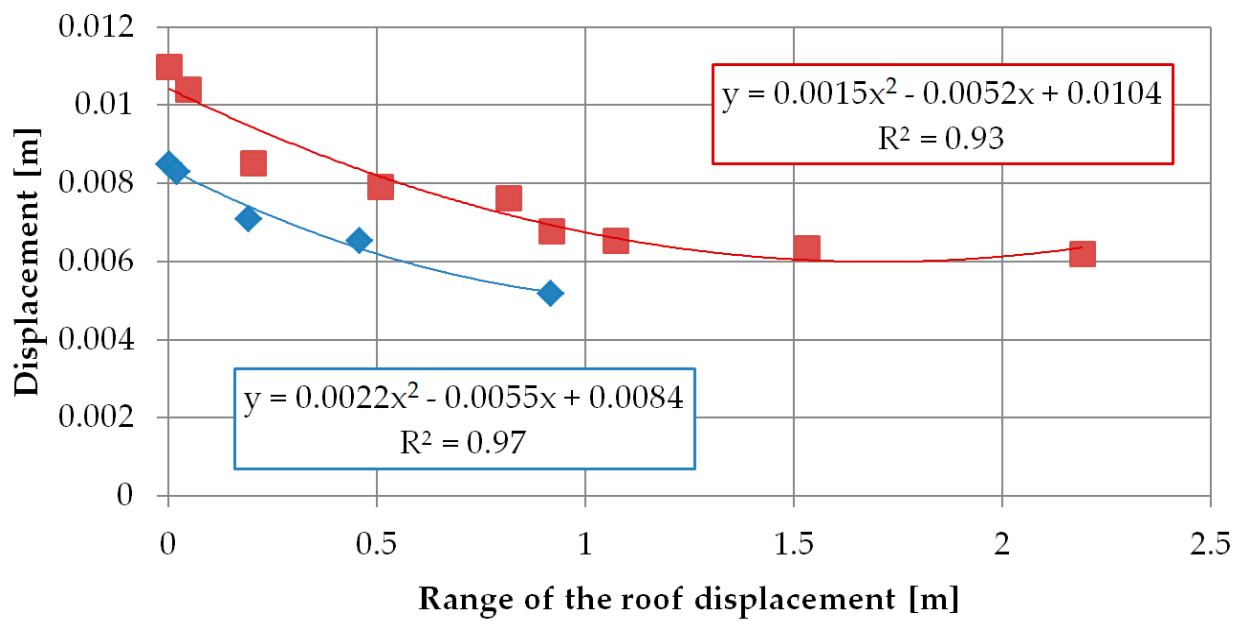

$\checkmark$ Variant I - L $=0.5 \mathrm{~m} \quad \square$ Variant I - L $=1.3 \mathrm{~m}$

(a)

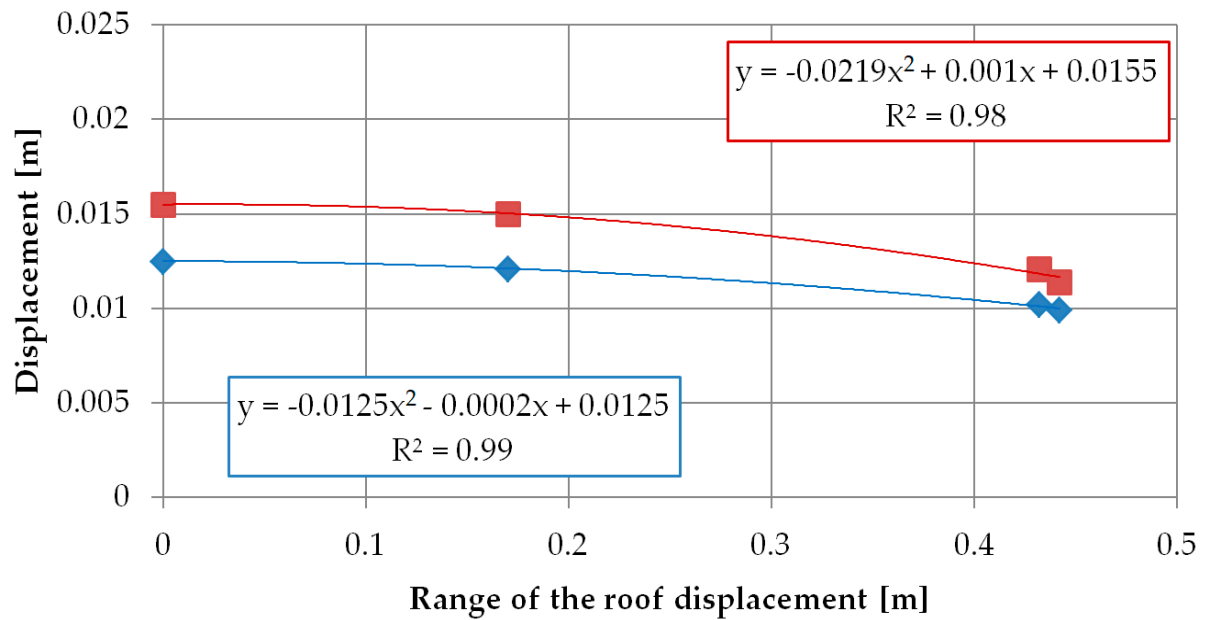

$\diamond$ Variant II - L $=0.5 \mathrm{~m} \square$ Variant II - L $=1.3 \mathrm{~m}$

(b)

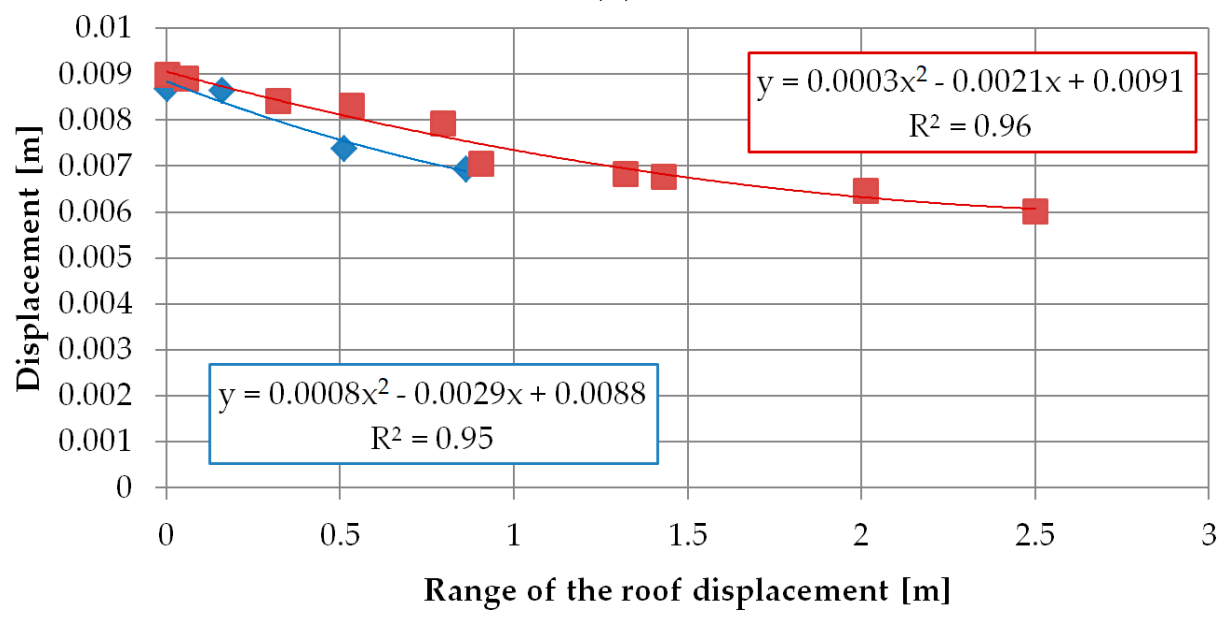

- Variant III - L = 0.5m $\square$ Variant III - L = $1.3 \mathrm{~m}$

(c)

Figure 12. Changes in the range of roof displacement an displacement in the roof of longwall working depending on the distance from coal face: (a)—variant I, (b) —variant II, (c)—variant III. 


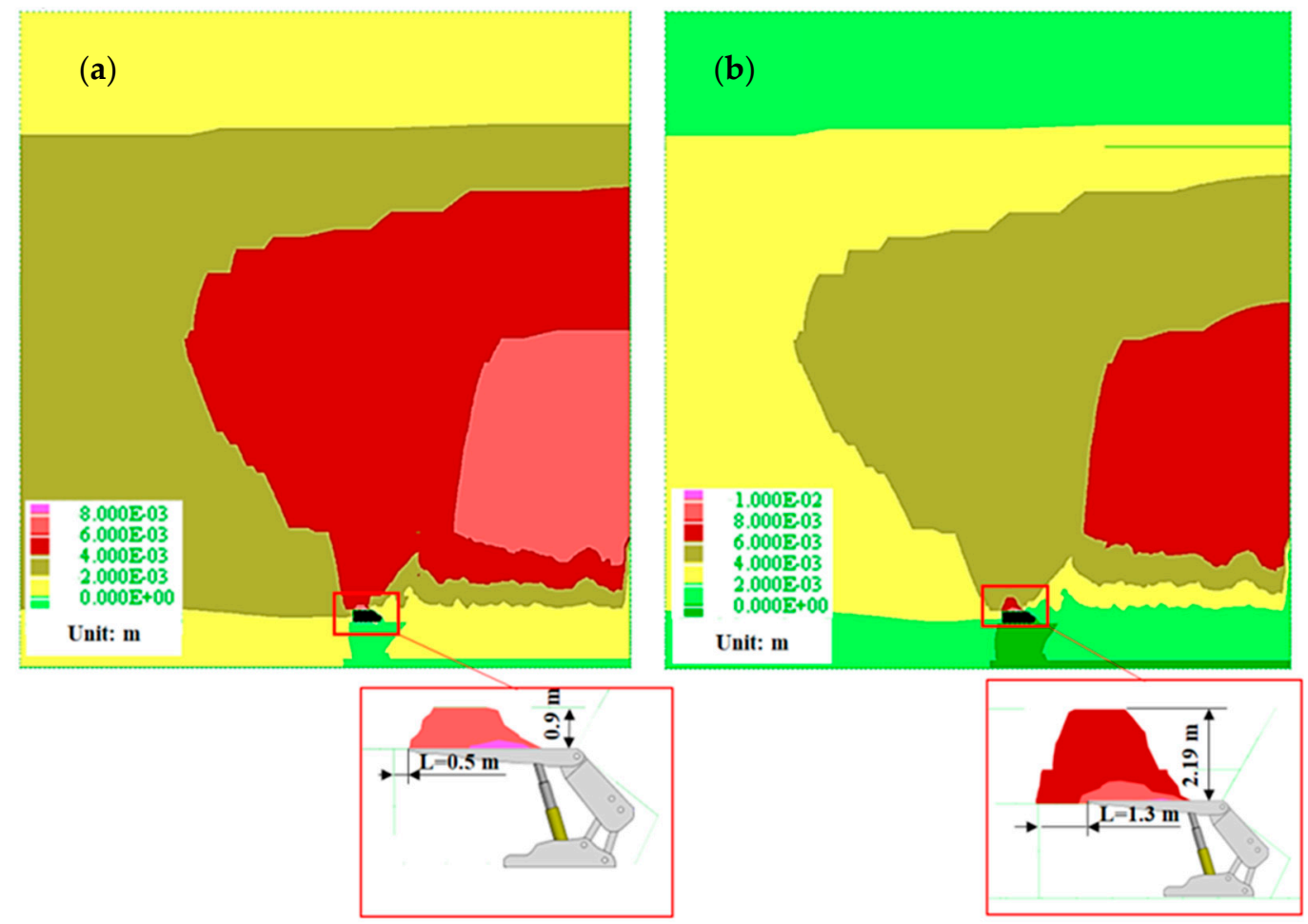

Figure 13. Vertical displacements in the rock mass model for the considered variant I, where: (a) before the web cut, (b) after the web cut.
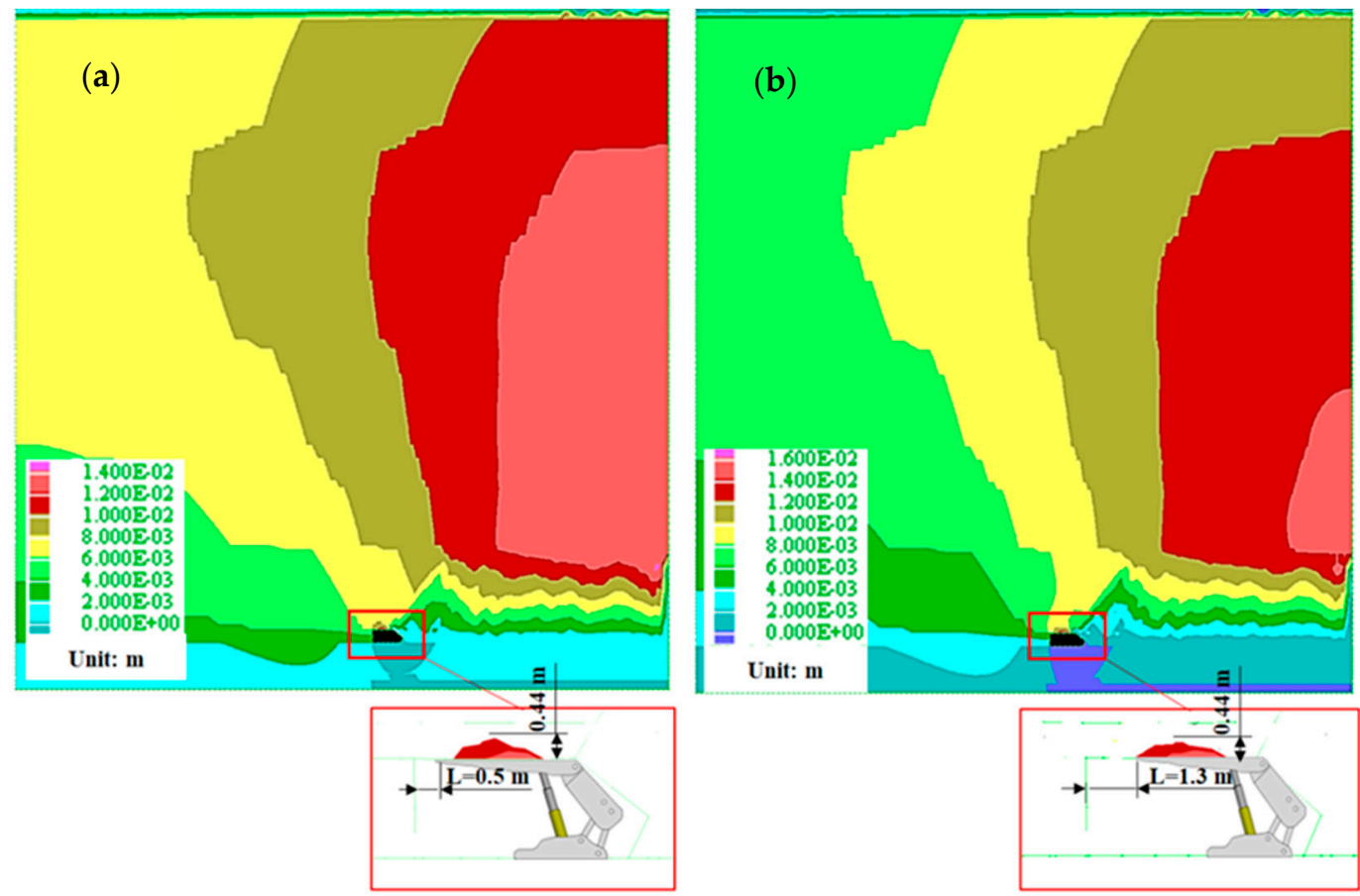

Figure 14. Vertical displacements in the rock mass model for the considered variant II, where: (a) before the web cut, (b) after the web cut. 

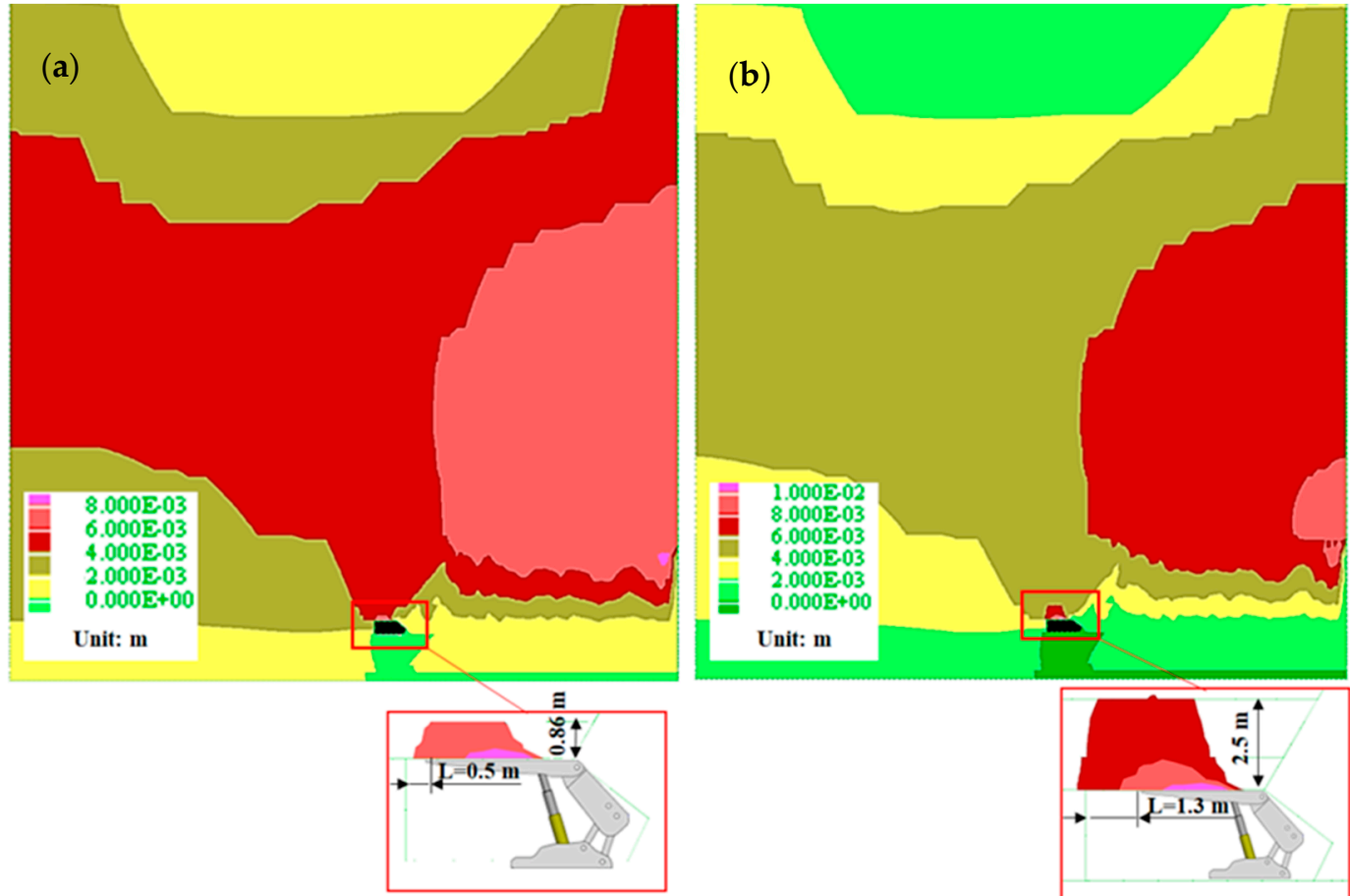

Figure 15. Vertical displacements in the rock mass model for the considered variant III, where: (a) before the web cut, (b) after the web cut.

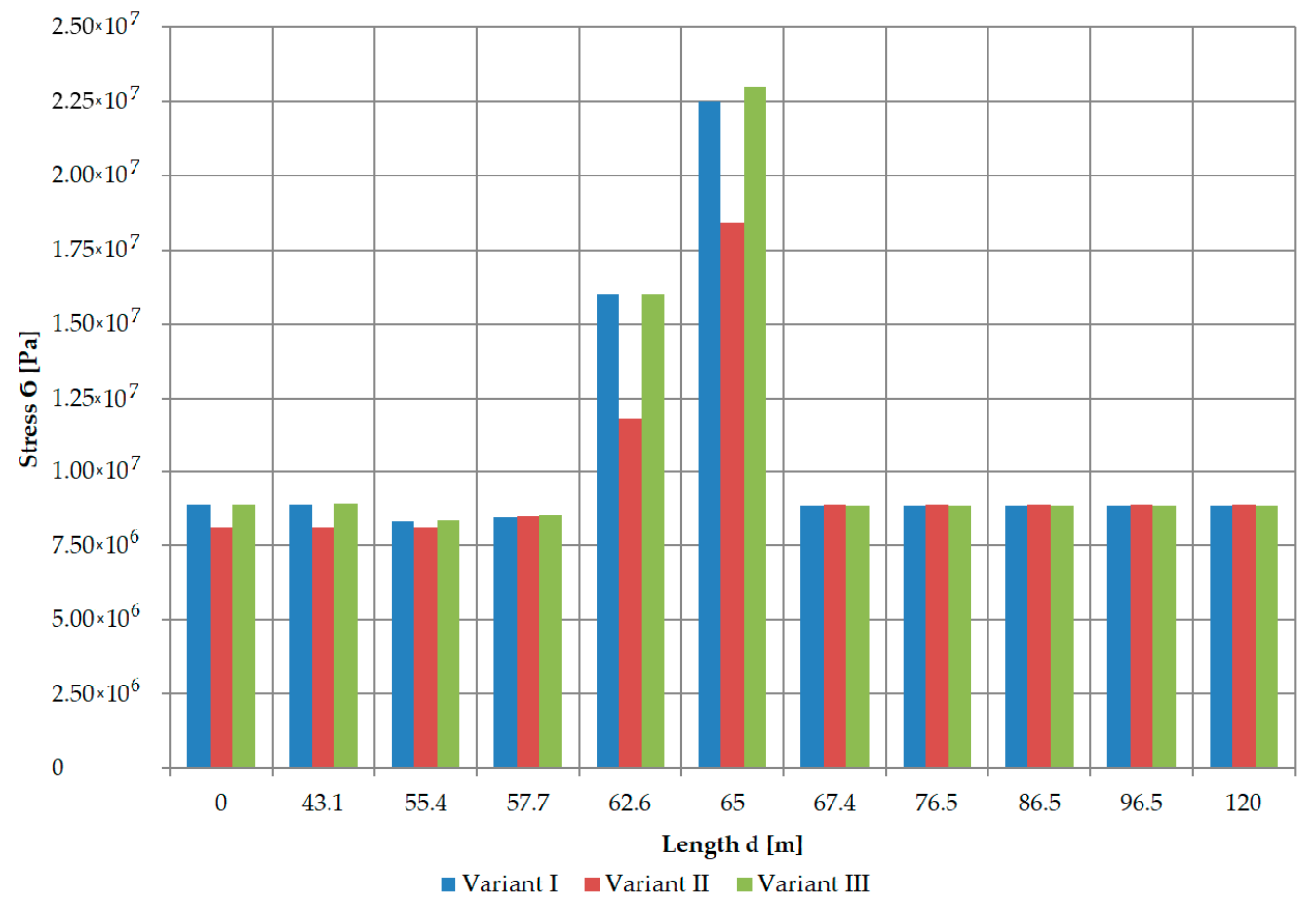

Figure 16. Stress distribution in the rock mass depending on the length of a longwall panel.

From the analysis of the data in Table 4 and the observation of the maps in Figure 12, it can be observed that the increase in the range of the roof displacement depends on the distance from coal face (Figure 11). An increase in the path, measured between the coal face and the beginning of the canopy, increases the value of the roof deflection, causing the displacement of roof rocks into the space of the longwall working. 
Figures 13-15 present a qualitative analysis of the displacement of the rock mass model in the form of a map of vertical displacements depending on the considered calculation variant.

The calculations show that the most favourable conditions for conducting the longwall are present in the case of exploitation in the conditions of rock mass relaxed by previous exploitation of the seam lying above (variant II-Figure 14). The goaf is regularly formed behind the powered roof supports, while in the main roof a relatively small displacement zone (approx. $0.44 \mathrm{~m}$ ) of low stability is formed. A significant increase in the height of this zone to approx. $0.9 \mathrm{~m}$ before the web cut to approx. $2.19 \mathrm{~m}$ after the web cut is observed in the case of a longwall in an unexplored rock mass (unexploited seam B, Figure 13-variant I) or $0.86 \mathrm{~m}$ and $2.5 \mathrm{~m}$ respectively, when the longwall front is within the influence range of the remaining longwall panel in the seam B (variant III). In these two cases, we see a significant effect of the width of the tip to face distance on the height of the vertical displacement zone produced, which can directly translate into the height of any fallout from the roof rock. Moreover, in these two cases, from the point of view of ensuring the stability of the longwall workings, the geomechanical situation is worse in the case of a residue left in the seam B, as larger and irregular displacements already occur at a considerable distance in front of the longwall face. These calculations confirm the in-situ observations during the operation of the longwall and the area (range) of rockfalls in the longwall, which was found by measurements when the longwall was in the range of the impact of the residue left in the seam B. In the section of the longwall run outside the impact zone of the residue, but in the zone of rock mass relaxation by exploitation of the seam B, no significant difficulties in ensuring the stability of the roof were found.

Comparative analysis the simulation results of the three schemes were done in Table 5.

Table 5. Comparative analysis the simulation results of the three schemes.

Variant I
Wefore the cut
After the

In the case of the seam A above which mining was carried out in the seam B, with the remaining part of this seam left, it is possible to observe the displacement of rock above the roof and behind the powered roof support (behind the 2-leg shield). The area of the formation of the roof fall is illustrated in Figure 14 as an area in red. Table 5 compares forecasted values of stress changes in rock mass model depending on the analysed calculation variant. Variant III after the web cut (third column and second row) in Table 5 reflects the numerical simulation with the in-situ observation shown in Figure 3. The data in Table 6 is characterized by the graph in Figure 16. 
Table 6. Distribution of pressure in the rock mass models in relation to the distance specified concerning the coal face for the considered calculation variants.

\begin{tabular}{cccccc}
\hline \multicolumn{2}{c}{ Variant I } & \multicolumn{2}{c}{ Variant II } & \multicolumn{2}{c}{ Variant III } \\
\hline $\mathbf{d}[\mathbf{m}]$ & $\mathfrak{S}[\mathbf{P a}]$ & $\mathbf{d}[\mathbf{m}]$ & $\mathfrak{S}[\mathbf{P a}]$ & $\mathbf{d}[\mathbf{m}]$ & $\mathfrak{S}[\mathbf{P a}]$ \\
\hline 0 & $8.88 \times 10^{6}$ & 0 & $8.14 \times 10^{6}$ & 0 & $8.89 \times 10^{6}$ \\
43.1 & $8.86 \times 10^{6}$ & 46.6 & $8.14 \times 10^{6}$ & 46.5 & $8.91 \times 10^{6}$ \\
55.4 & $8.32 \times 10^{6}$ & 58.9 & $8.14 \times 10^{6}$ & 56.3 & $8.36 \times 10^{6}$ \\
57.7 & $8.48 \times 10^{6}$ & 61.2 & $8.49 \times 10^{6}$ & 61.2 & $8.53 \times 10^{6}$ \\
62.6 & $1.60 \times 10^{7}$ & 66.1 & $1.18 \times 10^{7}$ & 63.6 & $1.60 \times 10^{7}$ \\
65 & $2.25 \times 10^{7}$ & 68.5 & $1.84 \times 10^{7}$ & 68.5 & $2.30 \times 10^{7}$ \\
67.4 & $8.83 \times 10^{6}$ & 70.9 & $8.89 \times 10^{6}$ & 70.9 & $8.83 \times 10^{6}$ \\
76.5 & $8.83 \times 10^{6}$ & 80 & $8.89 \times 10^{6}$ & 80 & $8.83 \times 10^{6}$ \\
86.5 & $8.83 \times 10^{6}$ & 90 & $8.89 \times 10^{6}$ & 90 & $8.83 \times 10^{6}$ \\
96.5 & $8.83 \times 10^{6}$ & 100 & $8.89 \times 10^{6}$ & 100 & $8.83 \times 10^{6}$ \\
120 & $8.83 \times 10^{6}$ & 120 & $8.89 \times 10^{6}$ & 120 & $8.83 \times 10^{6}$ \\
\hline
\end{tabular}

Symbols: d-length of the rock mass model (Figures 4-6), S-stress values.

The maximum stress in the seam A due to the influence of the mining front is:

- For variant I is $22.5 \mathrm{MPa}$, which is 2.5 times the initial stress in the rock mass analysed;

- For variant II is $18.4 \mathrm{MPa}$, which is 2.0 times the initial stress in the rock mass analysed;

- For variant III is $23.0 \mathrm{MPa}$, which is 2.6 times the initial stress in the rock mass analysed.

Table 7, for the assumed mechanical parameters of the rock mass, analyses were carried out to estimate values of geometrical parameters of the range of the roof displacement in the longwall workings, which made it possible to classify the longwall following the definition proposed in work [8]. Point classification of geometric parameters of rock fall proposed in the paper [8] in terms of its reach is as follows:

- Minor roof fall for a score weight less than 6;

- $\quad$ Medium roof fall for a score weight between $7 \div 9$;

- Major roof fall for a score weight between $10 \div 12$.

The point classification (point weight), which determines the range of variation of the geometric parameters of a circuit, is determined by the following criteria [8]:

a. For the parameter defining the height of the roof fall in the working of a longwall (x):

- For $\mathrm{x} \leq 1.0 \mathrm{~m}$ the weight of the points is 1 ;

- For $1.0 \mathrm{~m}<\mathrm{x} \leq 3.0 \mathrm{~m}$ the weight of the points is 3;

- $\quad$ For $>3.0 \mathrm{~m}$ the weight of the points is 6 .

b. For the parameter defining the distance from coal face $(y)$ :

- $\quad$ For $\mathrm{x} \leq 1.5 \mathrm{~m}$ the weight of the points is 1 ;

- For $1.5 \mathrm{~m}<\mathrm{x} \leq 2.0 \mathrm{~m}$ the weight of the points is 3;

- $\quad$ For $>2.0 \mathrm{~m}$ the weight of the points is 6 .

c. For the number of shields covered by the roof fall (i):

- $\quad$ For $\leq 3 \mathrm{~m}$ the weight of the points is 1 ;

- For $3<\mathrm{i} \leq 5$ the weight of the points is 3;

- $\quad$ For $\mathrm{i}>5 \mathrm{~m}$ the weight of the points is 6 .

The number of shields covered by roof fall is $i=28$. 
Table 7. Classification of rock falls occurring in the longwall workings under the influence of mining activity.

\begin{tabular}{|c|c|c|c|c|c|c|}
\hline $\begin{array}{c}\text { Path Width } \\
\text { L }[\mathrm{m}]\end{array}$ & Scheme & $\begin{array}{c}\text { Height } \\
x[\mathrm{~m}]\end{array}$ & Weight & $\begin{array}{l}\text { Width } \\
\mathrm{y}[\mathrm{m}]\end{array}$ & Weight & $\Sigma$ \\
\hline \multicolumn{7}{|c|}{ Variant I } \\
\hline 0.5 & & 0.9 & 1 & 0.5 & 1 & 8 \\
\hline 1.3 & & 2.19 & 3 & 1.3 & 1 & 10 \\
\hline \multicolumn{7}{|c|}{ Variant II } \\
\hline 0.5 & & 0.44 & 1 & 0.5 & 1 & 8 \\
\hline 1.3 & & 0.44 & 1 & 1.3 & 1 & 8 \\
\hline \multicolumn{7}{|c|}{ Variant III } \\
\hline 0.5 & & 0.86 & 1 & 0.5 & 1 & 8 \\
\hline 1.3 & & 2.50 & 3 & 1.3 & 1 & 10 \\
\hline
\end{tabular}

When the longwall is operated in an unrelaxed rock mass, as a result of the B seam lying above the exploited seam A (variant I), for a near face path width of $y=0.5 \mathrm{~m}$ (before the web cut) the weight attained 8 points (exposure of the longwall roof at $x=0.9 \mathrm{~m}$ ), which made it possible to classify the roof fall as a medium one, while for the width of the near face path equal $y=1.3 \mathrm{~m}$ (after the web cut) the weight reached 10 points (exposure of the longwall face to the height $x=2.19 \mathrm{~m}$ ), which made it possible to classify the roof fall as a major one.

In the case of a longwall in the exploited seam B lying above seam A (variant II), for the width of the near face path equal $y=0.5 \mathrm{~m}$ (before the web cut) the weight achieved was 8 points (exposure of the longwall roof at $x=0.44 \mathrm{~m}$ ), which allows the rock fall to be classified as a medium one, while for the width of the near face path equal $y=1.3 \mathrm{~m}$ (after the web cut) the weight achieved 8 points (exposure of the longwall face at $x=0.44 \mathrm{~m}$ ), which allows the roof fall to be classified as a medium one.

In the case of the driving of a longwall influenced by a remaining material of the seam B lying above the seam A (variant III), for the width of the near face path equal to $y=0.5 \mathrm{~m}$ (before the web cut) the weight obtained was 8 points (exposure of the longwall roof at $x=0.86 \mathrm{~m}$ ), which allows the roof fall to be classified as a medium one, while for the width of the near face path equal $y=1.3 \mathrm{~m}$ (after the web cut) the weight reached 10 points 
(exposure of the longwall face to the height $x=2.5 \mathrm{~m}$ ), which allows the roof fall to be classified as a major one.

Comparing the results of the numerical simulation for variant III with the results of underground (in-situ) measurements, comparable results were obtained, which makes it possible to state that one of the main reasons for the loss of roof stability of the longwall workings in the seam A was the influence of stresses caused by the unselected the seam B lying above the exploited the seam A.

\section{Conclusions}

This article presents model tests to determine the effect of mining conditions, in the form of remaining longwall panel lying above the exploited seam, on the possibility of a loss of stability (roof fall) in the longwall workings in the analyzed seam A. The authors discussed the geometry of the rock mass model under investigation, assumptions for the construction of the numerical model, and results of the numerical solution obtained. The classification of a longwall roof fall, based on geometrical parameters, was carried out in terms of its extent and the number of sections covered by the roof fall.

The results of the numerical modelling and in-situ observation allowed to formulate the following conclusions:

- The presence of unmined longwall panel is a factor influencing the longwall working stability due to disturbance of stress state.

- The results obtained from the model tests are confirmed by the observations made at the bottom of the mine and make it possible to state that it is possible to classify caving collapses based on the predicted geometrical parameters, which are the results of numerical calculations.

- $\quad$ Based on the results of numerical simulations carried out, it is possible to estimate the influence of changes in the length of the near face path of powered roof supports maintained during operation and the influence of operating conditions on the possibility and intensity of the formation of roof fall.

- Using numerical modelling, it is possible to predict the stability of longwall workings prior to their extraction.

- This will simultaneously allow for proper planning and design of safe exploitation, as well as limiting the potential effects of rockfalls in the workings.

Author Contributions: Conceptualization, S.R. and T.J.; methodology, T.J.; software, T.J.; validation, T.J., J.S. and A.W.; formal analysis, D.B.; investigation, T.J.; resources, J.S.; data curation, J.Ś.; writingoriginal draft preparation, T.J.; writing-review and editing, T.J.; visualization, T.J.; supervision, S.R.; project administration, T.J.; funding acquisition, J.Ś. All authors have read and agreed to the published version of the manuscript.

Funding: This research was funded by the Ministry of Science and Higher Education, Poland, grant number 11804039-152.

Institutional Review Board Statement: Not applicable.

Informed Consent Statement: Not applicable.

Data Availability Statement: Data available on request due to restrictions eg privacy or ethical.

Acknowledgments: The work was conducted as part of statutory research at the Central Mining Institute (No. 11804039-152), financed by the Ministry of Science and Higher Education, Poland.

Conflicts of Interest: The authors declare no conflict of interest.

\section{References}

1. Janoszek, T. The Assessment of Longwall Working Stability Based on the Mohr-Coulomb Stress Criterion-Numerical Analysis. Arch. Min. Sci. 2020, 65, 493-503. [CrossRef]

2. Masny, W. Powered support in dynamic load conditions-Numerical analysis. Arch. Min. Sci. 2020, 65, 453-468. [CrossRef] 
3. Nguyen, P.; Olczak, T.; Rajwa, S. An investigation of longwall failure using 3D numerical modelling-A case study at a copper mine. Studia Geotech. Mech. 2021, 43, 389-410. [CrossRef]

4. Prusek, S. The factors causing roof fall occurrences in longwall faces with natural roof caving. Przeglad Górniczy 2014, 3, 71-78. (In Polish)

5. Prusek, S. Stability of Longwall Workings during Exploitation of Hard Coal Seams with Caving; Central Mining Institute: Katowice, Poland, 2016. (In Polish)

6. Walentek, A. Analysis of the applicability of the convergence control method for gateroad design based on conducted underground investigations. Arch. Min. Sci. 2019, 64, 765-783. [CrossRef]

7. Cichy, T.; Prusek, S.; Świątek, J.; Apel, D.; Pu, Y. Use of Neural Networks to Forecast Seismic Hazard Expressed by Number of Tremors Per Unit of Surface Use of Neural Networks to Forecast Seismic Hazard Expressed by Number of Tremors Per Unit of Surface. Pure Appl. Geophys. 2020, 177, 1-9. [CrossRef]

8. Prusek, S. Classification of roof rocks falls in the longwalls with caving. Wiadomości Górnicze 2014, 6, 325-334. (In Polish)

9. Prusek, S.; Masny, W.; Walentek, A. Numerical modeling of the rock mass around an excavation exposed to mining-induced pressure. Górnictwo Geoinżynieria 2007, 31, 475-483. (In Polish)

10. Prusek, S.; Masny, W. Analysis of Damage to Underground Workings and Their Supports Caused by Dynamic Phenomena. J. Min. Sci. 2015, 51, 63-72. [CrossRef]

11. Rajwa, S.; Prusek, S.; Walentek, A.; Płonka, M. The influence of selected factors on cooperation of a powered support with the strata and the conditions of long walling. Wiadomości Górnicze 2015, 66, 533-543. (In Polish)

12. Sasaoka, T.; Mao, P.; Shimada, H.; Hamanaka, A.; Oya, J. Numerical Analysis of Longwall Gate-Entry Stability under Weak Geological Condition: A Case Study of an Indonesian Coal Mine. Energies 2020, 13, 4710. [CrossRef]

13. Rajwa, S. The Influence of the Geometrical Construction of the Powered Roof Support on the Loss of a Longwall Working Stability Based on the Practical Experience. Arch. Min. Sci. 2020, 65, 511-529. [CrossRef]

14. Rajwa, S.; Świątek, J.; Walentek, A.; Wrana, A. The analysis of causes of roof fall occurrence in caving longwalls with the application of Ishikawa diagram. Przegląd Górniczy 2018, 74, 8-15. (In Polish)

15. Prusek, S.; Rajwa, S.; Wrana, A.; Krzemień, A. Assessment of roof fall risk in longwall coal mines. Int. J. Min. Reclam. Environ. 2017, 31, 558-574. [CrossRef]

16. Świątek, J.; Janoszek, T.; Cichy, T.; Stoiński, K. Computational Fluid Dynamics Simulations for Investigation of the Damage Causes in Safety Elements of Powered Roof Supports-A Case Study. Energies 2021, 14, 1027. [CrossRef]

17. Itasca. UDEC Version 4.0. User's Manual; Itasca: Minneapolis, MN, USA, 2004.

18. Bui, M.T.; Le, T.D.; Vo, T.H. Stress Distribution Around Mechanized Longwall Face at Deep Mining in Quang Ninh Underground Coal Mine. Inżynieria Miner. J. Pol. Miner. Eng. Soc. 2021, 1, 167-176. [CrossRef]

19. Shi, X.; Jing, H.; Zhao, Z.; Gao, Y.; Zhang, Y.; Bu, R. Physical Experiment and Numerical Modeling on the Failure Mechanism of Gob-Side Entry Driven in Thick Coal Seam. Energies 2020, 13, 5425. [CrossRef]

20. Singh, M.; Singh, B. Laboratory and Numerical Modelling of a Jointed Rock Mass. In Proceedings of the 12th International Conference on Computer Methods and Advances in Geomechanics, Goa, India, 1-6 October 2008; p. 2.

21. Singh, G.S.P.; Singh, U.K. A numerical modeling approach for assessment of progressive caving of strata and performance of hydraulic powered support in longwall workings. Comp. Geotech. 2009, 36, 1142-1156. [CrossRef]

22. Biliński, A. Method of Selection of Longwall Face and Roadway Supports for the Paneling Conditions; Scientific Monographies CMG KOMAG z.11; CMG Komag: Gliwice, Poland, 2005. (In Polish)

23. Huang, Y.; Li, J.; Song, T.; Kong, G.; Li, M. Analysis on Filling Ratio and Shield Supporting Pressure for Overburden Movement Control in Coal Mining with Compacted Backfilling. Energies 2017, 10, 31. [CrossRef]

24. Yang, J.; Wang, H.; Wang, Y.; Liu, B.; Hou, S.; Cheng, Y. Stability Analysis of the Entry in a New Mining Approach Influenced by Roof Fracture Position. Sustainability 2019, 11, 6349. [CrossRef] 